DOI 10.15593/2224-9354/2017.2.10

УДК 316.354

Л.А. Белова, М.А. Ромашова

\title{
ЛОГОТИП: К ВОПРОСУ СЕМИОТИЧЕСКОГО ВЫБОРА
}

В статье исследуется логотип как инструмент имиджевой рекламы. Механизм создания рекламы обращен к природе семиотических знаков, понимание их функций в социуме позволяет выявить семиотическую эффективность логотипов и как продуктов деятельности и как носителей информации о компании, в том числе о ее продуктах. В статье описывается эксперимент, цель которого понять, какой семиотический знак вызывает наибольшее доверие потребителя, а значит, эффективнее представляет компанию, ее продукты и лучше продает товар.

Проведен анализ эффективности логотипов разной семиотической природы (знаки-иконы, знаки-индексы, знаки-символы) на примере пищевых компаний Пермского края. Онлайн-анкетирование выявило тенденции большей/меньшей эффективности конкретного семиотического знака как основы создания логотипа пищевой компании и, следовательно, эффективности ее имиджевой рекламы. Анализ показал, что наиболее эффективными при создании логотипов являются знаки-индексы и знаки-иконы: они легки для запоминания и интерпретации. Это обусловливает финансовоэкономическую целесообразность выбора знаков-индексов и знаков-икон, поскольку прямое изображение (икона) или указатель (индекс) адекватно ориентируют покупателя именно на пищевой продукт. Эстетическая привлекательность таких знаков для потребителя зависит от грамотной разработки их визуальной составляющей, что тоже предполагает учет семиотической природы логотипа.

Для непищевой рекламы выявлена тенденция востребованности (понятности и привлекательности для покупателей) знаков-символов, которые дают возможность использования их культурносмыслового потенциала в продвижении товаров.

Ключевые слова: эффективность коммуникации, имиджевая реклама, семиотика, знак, кодирование, декодирование, логотип.

Введение. В современной действительности роль имиджевой рекламы все более очевидна, а ее влияние на формирование массового и индивидуального сознания общества все более масштабно.

Логотип можно рассматривать как часть имиджевой рекламы, одной из функций которой является выработка и фиксация у целевых аудиторий ассоциаций компании с ее логотипом (товарным знаком) и группой товаров, которые она производит. Имиджевой рекламой еще называют корпоративную или брендинговую рекламу. Поэтому знание причин, приемов и способов воздействия рекламы заставляет глубже смотреть на ее связь с семиотикой. По мнению Г.Г. Почепцова, семиотическое изучение рекламного текста «неизбежно», поскольку реклама - многоканальная коммуникация [1, с. 193]. Ставший сегодня классическим семиотический анализ рекламного плаката фирмы «Пандзани», осуществленный Р. Бартом в далеком 1964 году, - это

() Белова Л.А., Ромашова М.А., 2017

Белова Лариса Александровна - канд. филол. наук, доцент кафедры «Иностранные языки и связи с общественностью» ФГБОУ ВО «Пермский национальный исследовательский политехнический университет», e-mail: fipp@pstu.ru.

Ромашова Мария Александровна - студентка 4 курса специальности «Реклама и связи с общественностью» ФГБОУ ВО «Пермский национальный исследовательский политехнический университет», e-mail: fipp@pstu.ru. 
анализ рекламы как семиотической модели, модели, констатирующей (и закрепляющей) определенные представления о жизни общества [2, с. 298].

Среди российских исследований данной тематики необходимо назвать коллективную монографию Н. Павловой, Т. Пашкевич и М. Старлетова «Семиотика и реклама: Общенаучные и прикладные аспекты» [3], работы Г.Г. Почепцова [1] и Е.А. Елиной [4], в которых реклама рассматривается как коммуникативная многоканальная технология и изучаются ее семиотические возможности воздействия. О семиотике и каналах трансляции медиарекламной картины мира пишет Е.Н. Ежова [5]; визуальная специфика рекламной коммуникации описывается в работах В.М. Розина и Е.В. Медведевой [6, 7]. Инструментарий и функции рекламы как закономерные механизмы экономического процесса изучают А.В. Катернюк, А.А. Романов, О.А. Феофанов [8-10].

Эффективное рекламное сообщение и его адекватное (т.е. тоже эффективное) восприятие потребителем предполагает понимание сущности такого семиотического понятия, как знак, служащего для обозначения, представления, замещения чего-либо другого. «Знак есть все, что может рассматриваться как существенно подменяющее что-то еще» [11]. Общепризнанная и до сих пор работающая (несмотря на ее погрешности и последующие уточнения) классификация знаков предложена Ч. Пирсом во второй половине XIX века и предполагает разделение знаков на иконические, индексальные и символические [12, с. 76].

Иконь - знаки-изображения, обладают физическим сходством с обозначаемыми объектами и могут использоваться как их «заместители», поскольку формируются на основе подобия формы и денотата. Индексы - это указательные знаки, форма и денотат находятся в «отношениях пространственновременной смежности» [4, с. 36], отношения могут быть причинно-следственными или ассоциативными. Символь - это условные знаки, поскольку форма и денотат не имеют прямой связи, то они получают свое значение исключительно на основании конвенции.

Изучая рекламу как коммуникативный феномен и как многоканальную технологию, специалисты все чаще обращают внимание на механизм получения информации, а практики-рекламщики хотят получить ответ на вопрос, какие семиотические инструменты стимуляции интереса покупателя наиболее эффективны.

В статье представлены результаты эксперимента, позволяющего ответить на вопрос, какой вид знака оказывается наиболее эффективным в процессе создания рекламного продукта. Мы исходили из того, что характеристики знаков лучше всего проявляются в условиях способности/неспособности незнакомой аудитории адекватно интерпретировать тот или иной знак.

Среди трех компонентов рекламного сообщения (вербальный текст, визуальный ряд, звучание) главенствующая роль отдается визуальным изображениям в силу того, «что они обрабатываются иным полушарием головного мозга, не допуская той меры рационализации при восприятии, которая имеет место в случае восприятия вербального текста» [1, с. 296].

PNRPU Sociology and Economics Bulletin. 2017. No. 2 
Методика и материал исследования. Материалами исследования послужили данные онлайн-анкетирования, проведенного при помощи онлайнсервиса survio. Опрошено 100 респондентов: 62 женщины и 38 мужчин в возрасте от 18 до 35 лет с высшим и незаконченным высшим образованием.

Анкета включала 11 вопросов. Анализу подверглись логотипы предприятий Пермского края разной семиотической природы: 3 иконы - ОАО «Молкомбинат Кунгурский»; кондитерская фабрика «Пермская»; ООО «Восточный», производитель мясной продукции, - филиал Краснокамского мясокомбината; 3 индекса - ООО «Маслозавод Нытвенский»; мясоперерабатывающий завод «Телец» (Кунгур); ОАО «Птицефабрика Пермская»; 3 символа ОАО «Покровский хлеб» (Пермь); ОАО «Пермалко», производитель крепкого алкоголя; ООО «Суксунские минеральные воды». Из логотипов предприятий были изъяты названия компаний с целью установления узнаваемости логотипа и его семиотической значимости.

Была проанализирована эффективность семиотических знаков при создании и потреблении логотипов 9 пермских предприятий (рис. 1):

1) ОАО «Молкомбинат Кунгурский»;

2) Кондитерская фабрика «Пермская»;

3) ООО «Маслозавод Нытвенский»;

4) Мясоперерабатывающий завод «Телец» (Кунгур);

5) ОАО «Покровский хлеб» (Пермь);

6) ОАО «Пермалко», производитель крепкого алкоголя;

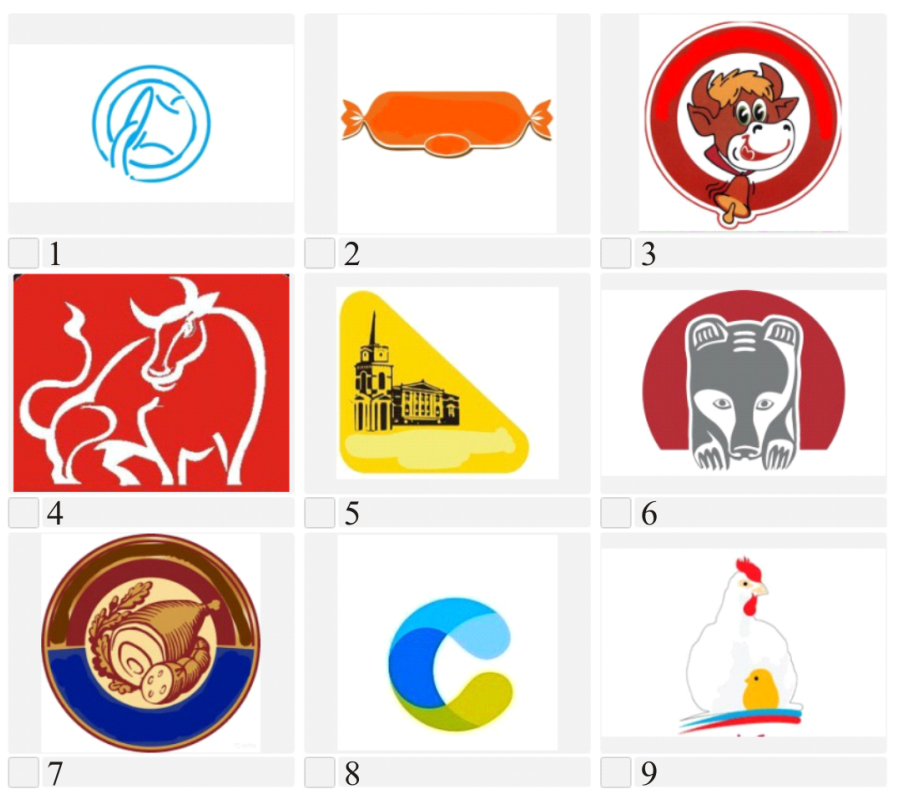

Рис. 1. Логотипы предприятий 
7) ООО «Восточный», филиал Краснокамского мясокомбината, производитель мясной продукции;

8) ООО «Суксунские минеральные воды»;

9) ОАО «Птицефабрика Пермская».

Результаты исследования. Первый вопрос анкеты - «Отметьте те предприятия, продукция которых вам хорошо известна» - выявлял уже знакомые потребителям логотипы (рис. 2).

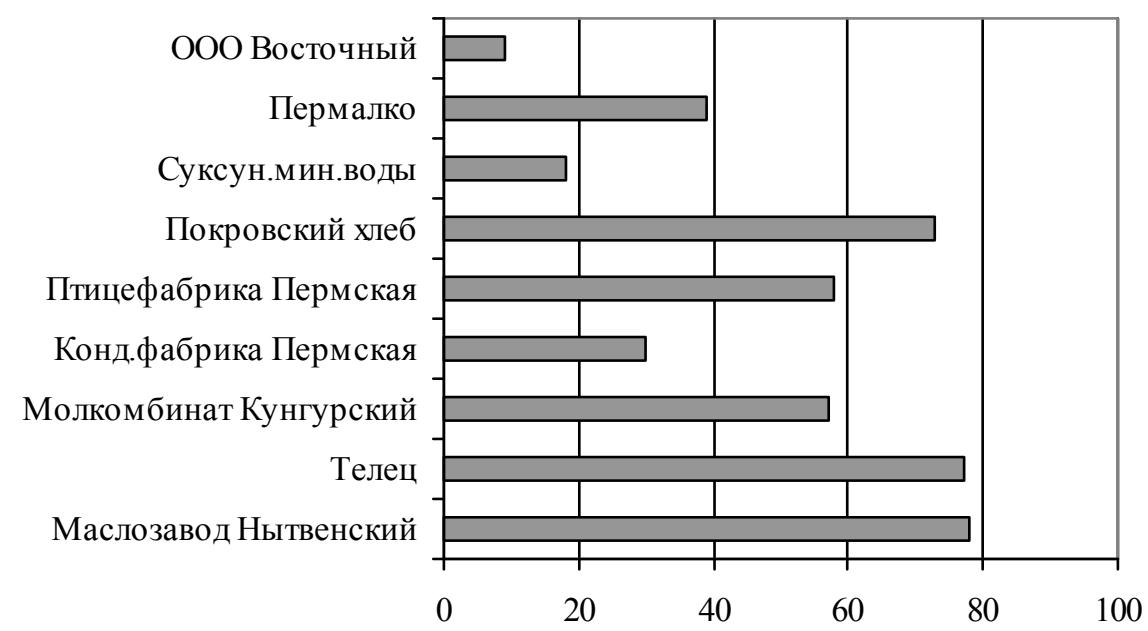

Рис. 2. Узнаваемость логотипов

Результаты показали, что наиболее узнаваемыми оказались логотипы хлебокомбината «Покровский хлеб» (73 \%), мясоперерабатывающего завода «Телец» $(77 \%)$ и маслозавода «Нытвенский» $(78 \%)$.

Большинство респондентов (73 \%) ответили, что знают, каким предприятиям принадлежат данные логотипы. Отметим, что первые два построены на основе знаков-индексов (указатели), а логотип «Покровский хлеб» - на основе знакасимвола. Некоторые респонденты (18 \%) узнали логотип ООО «Суксунские минеральные воды», построенный как знак-символ. И только $9 \%$ респондентов узнали логотип ООО «Восточный» (филиал Краснокамского мясокомбината, производитель мясной продукции), построенный на основе знака-иконы.

Анализ результатов первого опроса показывает, что знаки-индексы легче запоминаются и опознаются благодаря ассоциативной связи с денотатом. Другими словами, индексальный знак означает то, на что он в данный момент направляет внимание (указывает). Логотип маслозавода «Нытвенский» направляет наше внимание на то, что ассоциативно связано с коровой: молоко $>$ масло>сметана и т.п. Логотип мясоперерабатывающего завода «Телец» порождает ассоциации, связанные с быком/коровой: мясо> колбаса> балык и т.п. Но предшествующие знания о корове/быке могут сфокусироваться в конкретные 
ассоциации только после «прочтения» конкретного визуального изображения. В противном случае это могут быть самые произвольные ассоциации.

Эксперимент № 1 оценивал степень адекватности интерпретации иконических знаков. Респонденты отвечали на вопрос: «Какую продукиию может выпускать предприятие с таким логотипом?». Было получено следующее распределение правильных ответов, \%:

ОАО «Молкомбинат Кунгурский» .97

ООО «Восточный», производитель мясной продукции ................94

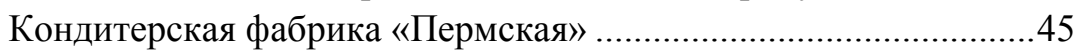

Средний показатель $.78,7$

Логотипы-иконы правильно поняты в 78,7 \% случаях. Иконический знак, как правило, легко и адекватно интерпретируются за счет схожей формы с денотатом. Вместе с тем можно заметить относительно низкий процент правильной интерпретации логотипа кондитерской фабрики «Пермская» - 45 \%. Респонденты приняли знак конфеты за знак колбасы. Данный пример позволяет говорить, что выбор иконического знака для создания рекламного продукта, в нашем случае логотипа, нельзя считать беспроигрышным.

Эксперимент № 2 выявлял степень понимания знаков-индексов. Респонденты отвечали на вопрос: «Какую продукцию может выпускать предприятие с таким логотипом?». Количество правильных ответов, \%, следующее:

ООО «Маслозавод Нытвенский». .86

Мясоперерабатывающий завод «Телец» ...................................99

$\mathrm{OAO}$ «Пицефабрика Пермская» ....................................................96

Средний показатель $.90,7$

Данные показывают, что в 90,7 \% случаях знак-индекс был правильно понят респондентами. Результат закономерен, поскольку логотипы маслозавода «Нытвенский» и мясоперерабатывающего завода «Телец» хорошо узнавались: 77 и $78 \%$ соответственно (см. рис. 2). А вот логотип птицефабрики «Пермская» не имел высокую узнаваемость - 59 \% (см. рис. 2). Несмотря на это, знак был правильно понят в $96 \%$ случаях. Выстраивание ассоциативной связи курииа, иыпленок > яйцо, мясо курицы помогло потребителю адекватно интерпретировать знак.

Эксперимент № 3 выявлял степень понимания знаков-символов. Респонденты отвечали на вопрос: «Какую продукиию может выпускать предприятие с таким логотипом?». Количество правильных ответов, \%:

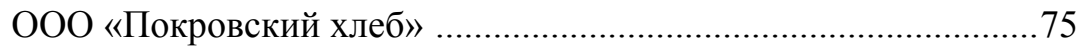

ООО «Суксунские минеральные воды» .......................................3

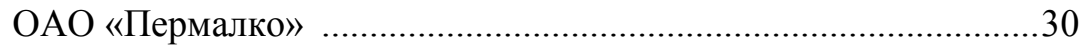

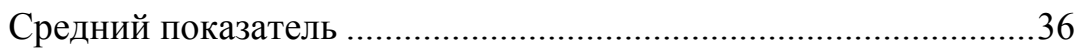


Знак-символ правильно понят в 36 \% случаев. Процент адекватной интерпретации очень низкий, если учесть, что респондентам были известны данные логотипы. Напомним, что узнаваемость логотипа ООО «Покровский хлеб» составила 73 \%, а логотипа ОАО «Пермалко» - 39 \% (см. рис. 2). В случае с логотипом ООО «Суксунские минеральные воды» ситуация, на наш взгляд, закономерная: 18 \% узнаваемости не могут привести к правильной, адекватной интерпретации.

Конечно, знак-символ сложен для понимания и, следовательно, для интерпретации. Знак-символ практически невозможно самостоятельно интерпретировать, не имея никакой сопутствующей информации, не имея предварительной «договоренности» о том, что за этой формой закрепляется определенное содержание. Так, логотип ООО «Суксунские минеральные воды» никак не указывает на товар, который выпускает предприятие. Покупатель может представить что угодно: например, некое художественное сообщество, объединяющее любителей живописи, либо какую-нибудь благотворительную организацию, деятельность которой направлена на расширение человеческого потенциала, либо вспомнить логотип тарифа «Радуга»у оператора мобильной связи «Уралсвязьинформ». В данном логотипе кроме голубого цвета ничто не может натолкнуть на идею воды, тем более минеральной. Нужна фоновая, сопутствующая информация, которая бы позволяла нам «договориться» или «согласиться», что логотипом ООО «Суксунские минеральные воды» может/должно быть именно такое визуальное решение.

В интерпретации логотипа ОАО «Пермалко» неочевидно, что именно за медведем должно закрепляться значение «крепкий алкогольный напиток». Полагаем, что такому «соглашению» мешает утвердившийся в сознании россиян факт, что медведь - национальный символ России, что он - символ силы характера и крепости духа русского человека. Не случайно, медведь включается в логотипы спортивных организаций и обществ, деятельность которых основана на воспитании крепости духа человека, его силы и характера. Нередко это совпадает и с территориальной принадлежностью таких организаций. Так, в Перми есть гандбольная команда «Пермские медведи» и баскетбольная команда «Парма», в логотипы которых включен образ медведя.

Высокий процент (73 \%) интерпретационной точности логотипа ОАО «Покровский хлеб» объясняется, на наш взгляд, существованием такой сопутствующей информации. Уже на протяжении двух десятков лет у пермяков на столах хлебобулочная продукция этого комбината. Изображение краевой художественной галереи и театра оперы и балета им. П.И. Чайковского, конечно, не наталкивает на мысль о хлебобулочных изделиях. Но это устоявшиеся символы Перми, где одна из лучших в России балетная труппа и одно из лучших в России собрание картин. Значит, и хлеб ОАО «Покровский хлеб» тоже лучший.

Последний вопрос онлайн-анкеты предлагал респондентам отметить логотипы, которые им нравятся (рис. 3).

PNRPU Sociology and Economics Bulletin. 2017. No. 2 


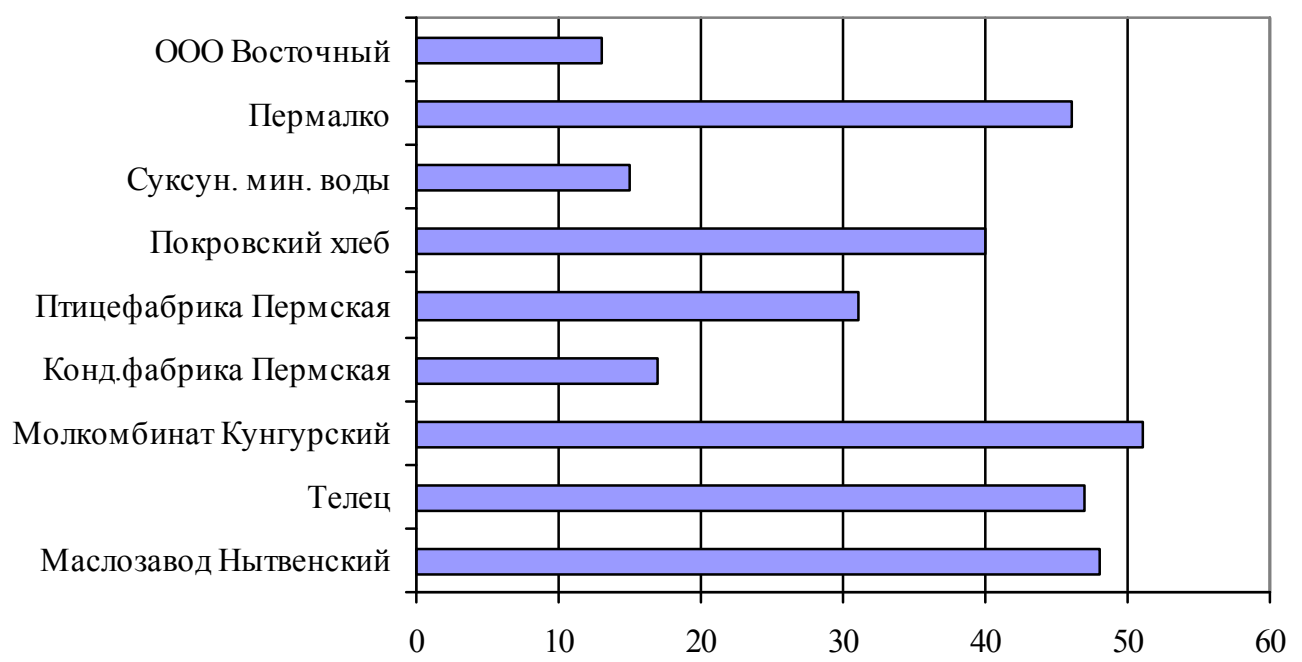

Рис. 3. Оценка логотипов

Как наиболее привлекательные респонденты определили логотипы компании «Телец» - 47 \% , маслозавода «Нытвенский» - 48 \% и молкомбината «Кунгурский»- $51 \%$.

Bbыводы. Итак, на протяжении всего опроса на первых позициях оказываются логотипы пищевых компаний «Телец» и «Нытвенский»: они хорошо понимаются потребителями и кажутся им наиболее привлекательными. Напомним, что логотипы этих компаний содержат знаки-индексы. Есть основания говорить, что выбор знака-индекса для создания и интерпретации логотипа может иметь определенные преимущества.

Природа знака-индекса позволяет его легко интерпретировать. Подтверждение находим в результатах нашего онлайн-опроса. Индексы быстро создают в сознании потребителя определенный образ, позволяя соотнести его с референтом без особого умственного усилия. Но стоит помнить об индивидуальности человека, своеобразии его жизненного опыта и картины мира, поэтому индекс, казалось бы, однозначный знак может вызывать различные ассоциации и по-разному декодироваться. Так, логотип птицефабрики «Пермская» не набрал и 60 \% узнаваемости.

Главным преимуществом иконического знака является возможность прямой передачи какой-либо идеи и, как следствие, легкой ее интерпретации. Такая природа знака-иконы провоцирует его на возникновение чувственного образа. Г.Г. Почепцов отмечает, что «нам сложно в принципе отрицать изображение, поскольку оно более реально в восприятии, чем вербальные характеристики. Его отрицание в какой-то мере и невозможно» [1, с. 296-297].

Здесь, как нам представляется, кроется и их «недостаток»: иконические знаки с их способностью вызывать мысленный образ подавляют воображение, вызывая в памяти моментальное изображение уже виденного. Что очевидно 
в случае с логотипом ООО «Восточный» (филиал Краснокамского мясокомбината, производитель мясной продукции), показавшим самый маленький процент узнаваемости - $9 \%$. Этот же логотип респонденты отмечают как менее всего понравившийся - $13 \%$. Скорее всего, респондентов не удовлетворила эстетическая реализация такой прямой передачи идеи колбасных изделий. Надо признать, что картинка скучная, несовременная и «невкусная». Слабая эстетическая составляющая и у логотипа кондитерской фабрики «Пермская» - 17 \%. Непривлекательность логотипа напрямую связана с его плохой узнаваемостью: изображение конфеты принято за изображение батона колбасы.

Говоря о преимуществах знаков-символов, помним, что они способны породить суждение и воздействовать на мышление человека, вызвать ту или иную реакцию и соответствующее поведение. С помощью символов выстраиваются устойчивые ассоциативные связи, которые создают уникальную систему метаязыка рекламы определенного бренда. Удачно выстроенный и удачно декодированный аудиторией символ в логотипе часто становится центром идентификации бренда, обеспечивая ему уникальную, ни на что не похожую форму. Таковыми, например, можно считать олимпийские кольца как символ летних и зимних Олимпиад и Олимпийского движения; олимпийского Мишку как символ Московской (русской) Олимпиады-80; голубь как символ мира, книга как символ знаний и многие другие.

Безусловно, у любого типа знака есть как ряд преимуществ, так и ряд недостатков. Апеллируя к результатам нашего опроса, приходим к выводу о том, что наиболее эффективными при создании логотипов являются знакииндексы и знаки-иконы. Они легко запоминаются и интерпретируются, и поэтому кажутся наиболее привлекательными. Людям свойственно выбирать то, что для них понятно.

Знак-символ тоже может быть понятен и, следовательно, воздействовать на потребителя. Оптимальный способ применения символов в логотипах - это воспользоваться уже существующими в сознании потребителя символическими идеями и образами. Подходящие символы можно найти практически в любом аспекте повседневной жизни или определить их по содержанию эстетических кодов. По мнению Я. Эллвуда, облегчает коммуникации и способствует повышению их эффективности «выбор наиболее релевантного, то есть наиболее соответствующего ожиданиям потребителей символического образа...» [13 , с. 91].

Как показывает опыт, для рекламы продуктов наиболее эффективны знаки-индексы и знаки-иконы при условии их грамотно разработанной эстетической составляющей. Выбор этих же знаков целесообразен и с финансовоэкономической стороны: прямое изображение (икона) или указатель (индекс) адекватно будут ориентировать покупателя именно на продукт. В рекламе непищевой востребованы будут знаки-символы, поскольку они будут продвигать ценности, а это требует большой работы по созданию и реализации сопутствующей информации.

PNRPU Sociology and Economics Bulletin. 2017. No. 2 


\section{Список литературы}

1. Почепцов Г.Г. Коммуникативные технологии двадцатого века. - М.: Рефл-бук, 1999. - 200 с.

2. Барт Р. Риторика образа // Барт Р. Избранные работы. Семиотика. Поэтика. - М., 1994. - 318 с.

3. Семиотика и реклама: общенаучные и прикладные аспекты: моногр. / Н.Г. Павлова, Т.В. Пашкевич, М.Г. Старолетов. - Барнаул: Изд-во Алт. гос. техн. ун-та, 2003. - $122 \mathrm{c}$.

4. Елина Е.А. Семиотика рекламы. - М.: Дашков и К ${ }^{\mathrm{O}}, 2009 .-136$ с.

5. Ежова Е.Н. Медиарекламная картина мира: структура, семиотика, каналы трансляции: автореф. дис. ... д-ра филол. наук. - Воронеж, 2010. - 60 с.

6. Розин В.М. Визуальная культура и восприятие. Как человек видит и понимает мир. - 3-е изд., стер. - М.: КомКнига, 2006. -224 с.

7. Медведева Е.В. Рекламная коммуникация. - М.: Эдиториал УРСС, 2008. $-280 \mathrm{c}$.

8. Катернюк А.В. Рекламные технологии: Коммерческая реклама. - Ростов н/Д: Феникс, 2001. - 320 с.

9. Романов А.А. Реклама: между социумом и маркетингом. - М.: Маркет ДС, 2002. $-300 \mathrm{c}$.

10. Феофанов О.А. Реклама: новые технологии в России. - СПб.: Питер, 2002. $-384 \mathrm{c}$.

11. Эко У. Отсутствующая структура. Введение в семиологию. - URL: http://socium.ge/downloads/komunikaciisteoria/otsutstvuiushaia\%20struktura\%20u mberto\%20eko.pdf (дата обращения: 10.08.2016).

12. Пирс Ч.С. Начала прагматизма: в 2 т. Т. 2 /пер. с англ. В.В. Кирющенко, М.В. Колопотина. Логические основания теории знаков. - СПб.: Лаборатория метафизических исследований философского факультета СПбГУ: Алетейя, 2000. - 352 с.

13. Эллвуд Я. 100 приемов эффективного брендинга. - СПб.: Питер, 2002. $-368 \mathrm{c}$.

\section{References}

1. Pocheptsov G.G. Kommunikativnye tekhnologii dvadtsatogo veka [Communicative technologies of the twentieth century]. Moscow, Refl-buk Publ., 1999, 200 p.

2. Bart R. Ritorika obraza [Rhetoric of the image]. Izbrannye raboty. Semiotika. Poetika. Moscow, 1994, 318 p.

3. Semiotika i reklama: obshchenauchnye i prikladnye aspekty: monografiia [Semiotics and advertising: general scientific and applied aspects]. Barnaul, Alt. gos. tekhn. un-t, 2003, 122 p. 
4. Elina E.A. Semiotika reklamy [Semiotics of advertising]. Moscow, Dashkov i Ko Publ., 2009, 136 p.

5. Ezhova E.N. Media-reklamnaia kartina mira: struktura, semiotika, kanaly transliatsii [Media-advertising picture of the world: structure, semiotics, broadcasting channels]. Abstract of Doctor's degree dissertation. Voronezh, 2010, $60 \mathrm{p}$.

6. Rozin V.M. Vizual'naia kul'tura i vospriiatie. Kak chelovek vidit i ponimaet mir [Visual culture and perception. How a person sees and understands the world]. 3rd ed. Moscow, KomKniga Publ., 2006, 224 p.

7. Medvedeva E.V. Reklamnaia kommunikatsiia [Advertising communication]. Moscow, Editorial URSS Publ., 2008, 280 p.

8. Katerniuk A.V. Reklamnye tekhnologii: Kommercheskaia reklama [Advertising technologies: commercial advertising]. Rostov-on-Don, Feniks Publ., 2001, 320 p.

9. Romanov A.A. Reklama: mezhdu sotsiumom i marketingom [Advertising: between the society and marketing]. Moscow, Market DS Publ., 2002, 300 p.

10. Feofanov O.A. Reklama: novye tekhnologii v Rossii [Advertising: new technologies in Russia]. Saint-Petersburg, Piter Publ., 2002, 384 p.

11. Eko U. Otsutstvuiushchaia struktura. Vvedenie v semiologiiu [Missing structure. Introduction to semiology]. Available at: http://socium.ge/downloads/ komunikaciisteoria/otsutstvuiushaia\%20struktura\%20umberto\%20eko.pdf (accessed 10 August 2016).

12. Pierce Ch.S. Logical foundations of the theory of signs. Dover Publications, Inc., 1958 [Russ. ed.: Nachala pragmatizma: v 2 t. T. 2. Logicheskie osnovaniia teorii znakov. Saint-Petersburg, Laboratoriia metafizicheskikh issledovanii filosofskogo fakul'teta SPbGU, Aleteiia Publ., 2000, 352 p.].

13. Ellvud Ia. 100 priemov effektivnogo brendinga [100 techniques of effective branding]. Saint-Petersburg, Piter Publ., 2002, 368 p.

Оригинальность статьи - $90 \%$

Получено 24.11.2016

L.A. Belova, M.A. Romashova

\section{LOGOTYPE: A MATTER OF SEMIOTIC CHOICE}

The article studies the use of logotypes as an image advertising tool. The mechanism of advertisement design reveals the nature of semiotic signs. Understanding their functions in the society helps to define the semiotic effectiveness of logotypes as the company's products as well as informationcarrying media. The article describes the experiment that analyzes, which of the semiotic signs has the highest credibility among consumers, and hence more effectively represents the company and sells its products.

PNRPU Sociology and Economics Bulletin. 2017. No. 2 
The authors analyze the effectiveness of logotypes that belong to various semiotic groups including icons, indexes and symbols. The analysis covers the food companies of Perm Krai. The results of the polling indicate the increase and decrease in the effectiveness of a certain semiotic sign as the basis for food company's logotype design, which results in the effectiveness of its image advertising. The analysis shows the most effective logotype signs are indexes and icons, as they are easy to understand and interpret. This determines the financial and economic efficiency of using such signs, as the direct images and indexes, able to focus clients on buying certain products. The aesthetic appeal of such signs for customers is determined by a smart design of the product's logotype visual presentation, which also implies taking its semiotic nature into account. Non-food products' advertisement demands using culture-oriented potential of signs for the product's promotion.

Keywords: communication effectiveness, image advertising, semiotics, sign, encoding, decoding, logotype.

Larisa A. Belova - Candidate of Philological Sciences, Associate Professor, Dept. of Foreign Languages and Public Relations, Perm National Research Polytechnic University, e-mail: fipp@pstu.ru.

Mariya A. Romashova - Undergraduate Student, Advertising and Public Relations, Perm National Research Polytechnic University, e-mail: fipp@pstu.ru. 